\title{
Clinical Reasoning: A 60-year-old man with arm weakness and numbness
}

Laura A. Foster, MD, Anthony A. Amato, MD, and Aaron L. Berkowitz, MD, PhD

Neurology ${ }^{\circledR}$ 2018;90:190-196. doi:10.1212/WNL.0000000000004867

\section{Section 1}

A 60 -year-old previously healthy man awoke with right arm pain and numbness. Opioids resulted in modest pain relief, but over the following weeks, the pain worsened. He began dropping things and had more difficulty writing, buttoning clothing, and opening jars. Cervical MRI demonstrated mild central canal stenosis and moderate foraminal stenosis at multiple levels, worse on the left. He received physical therapy and an epidural steroid injection for cervical radiculopathy, but his weakness worsened to near-paralysis of his right wrist and fingers.

The patient underwent C4-C7 anterior cervical discectomy and fusion without complication. About 2 weeks after surgery, he developed weakness in his right shoulder, increased tingling in his right hand, and new tingling and weakness in the left hand.

Because of persistently worsening symptoms, a neuromuscular consultation was obtained. Examination revealed atrophy of the distal right upper extremity primarily in the extensor forearm and bilateral scapular winging, right worse than left. Strength in the upper extremities was (Medical Research Council right/left): shoulder abduction 3-/5, shoulder external rotation $4 / 5$, elbow flexion $4 / 4+$, elbow extension $4 / 5$, forearm supination $2 / 4$, wrist extension $0 /$ 3 -, wrist flexion $4 / 4$, finger extension $0 / 0$, finger flexion (deep) $4-/ 4$, finger abduction $4 / 4$, thumb abduction $2 / 4$, thumb flexion $0 / 4$. In the lower extremities, strength was normal. The patient had areflexia in the upper extremities, $2+$ reflexes in the lower extremities, and flexor plantar responses. He had diminished sensation to pinprick, light touch, and temperature in the bilateral upper extremities (right more so than left), most prominent in the dorsum of the hands between the thumb and the index finger and over the deltoids. Vibration and proprioception were normal. Sensation was intact in the lower extremities. There was no spinal level. Mental status, cranial nerves, cerebellar function, and gait were normal.

\section{Questions for consideration:}

1. What is the localization of his deficits?

2. What additional testing would help refine the localization?

\author{
Correspondence \\ Dr. Foster \\ Ifoster7@mgh.harvard. \\ edu
}

GO TO SECTION 2

From the Department of Neurology, Brigham and Women's Hospital and Harvard Medical School, Boston, MA.

Go to Neurology.org/N for full disclosures. Funding information and disclosures deemed relevant by the authors, if any, are provided at the end of the article. 


\section{Section 2}

The muscle atrophy, sensory deficits, and absence of upper extremity reflexes suggest a peripheral process involving multiple nerve roots (C5-T1) or nerves (suprascapular, musculocutaneous, axillary, radial, median), or a brachial plexopathy (table e-1, links.lww.com/WNL/A76).

Severe pain at onset is typical for radiculopathies because of sensory nerve root irritation. Plexopathies associated with ischemia or inflammation such as immune-mediated brachial plexopathy (Parsonage-Turner syndrome) or diabetic radiculoplexus neuropathy are also associated with severe pain at the onset of weakness. Small fiber neuropathies are painful, but these are typically symmetric and distal in onset. Vasculitic neuropathy, which can present as multiple mononeuropathies, is also associated with severe pain.

Nerve conduction studies (NCS) and EMG were obtained approximately 3 months after symptom onset (table 1).

\section{Question for consideration:}

1. Localize the abnormalities on NCS and EMG.

GO TO SECTION 3 
Table 1 Nerve conduction studies and EMG

\begin{tabular}{|c|c|c|c|}
\hline SNAP & Peak latency (normal value), ms & Amplitude (normal value), $\mu \mathrm{V}$ & Conduction velocity (normal value), $\mathrm{m} / \mathrm{s}$ \\
\hline $\mathrm{R}$ median, digit 2 & $2.97(<3.5)$ & $7.5^{a}(>20)$ & $60.9(>48)$ \\
\hline L median, digit 2 & $2.81(<3.5)$ & $11.9^{\mathrm{a}}(>20)$ & $69.3(>48)$ \\
\hline R ulnar, digit 5 & $2.92(<3.1)$ & $15.0(>10)$ & $52.8(>48)$ \\
\hline L ulnar, digit 5 & $2.71(<3.1)$ & $15.1(>10)$ & $58.7(>48)$ \\
\hline $\mathrm{R}$ radial, snuff box & $N^{a}(<2.5)$ & $N R^{a}(>15)$ & $\mathrm{NR}^{\mathrm{a}}(>48)$ \\
\hline L radial, snuff box & $2.24(<2.5)$ & $12.3^{\mathrm{a}}(>15)$ & $61.9(>48)$ \\
\hline R sural, lateral malleolus & $3.44(<4.2)$ & $18.6(>5)$ & $51.7(>42)$ \\
\hline CMAP & Distal latency (normal value), ms & Amplitude (normal value), mV & Conduction velocity (normal value), $\mathrm{m} / \mathrm{s}$ \\
\hline R median, APB & $3.28(<4.5)$ & $8.9(>4)$ & $52.3(>48)$ \\
\hline L median, APB & $3.28(<4.5)$ & $9.8(>4)$ & $52.4(>48)$ \\
\hline R ulnar, ADM & $2.76(<3.6)$ & $10.8(>5)$ & $61.4(>48)$ \\
\hline L ulnar, ADM & $2.71(<3.6)$ & $12.2(>5)$ & $60.0(>48)$ \\
\hline $\mathrm{R}$ radial, EIP & $\mathrm{NR}^{\mathrm{a}}(<3.6)$ & $\mathrm{NR}^{\mathrm{a}}(>7)$ & $\mathrm{NR}^{\mathrm{a}}(>48)$ \\
\hline L radial, EIP & $2.71(<3.6)$ & $0.3^{a}(>7)$ & $57.6(>48)$ \\
\hline R peroneal, EDB & $3.91(<6.6)$ & $4.5(>2)$ & $39.2(>42)$ \\
\hline EMG & Spontaneous activity & Motor unit morphology & Recruitment pattern \\
\hline $\mathrm{R}$ rhomboids & $\mathrm{b}$ & Normal & Normal \\
\hline$R$ infraspinatus & None & Normal & Normal \\
\hline$R$ deltoid & Fibs/PSWs & Normal & Mildly reduced \\
\hline R biceps & None & Large-amplitude, long-duration & Mildly reduced \\
\hline R triceps & None & Normal & Normal \\
\hline R pronator teres & Fibs/PSWs & No units & No units \\
\hline R EDC & Fibs/PSWs & No units & No units \\
\hline R FDI & None & Normal & Normal \\
\hline R APB & None & Normal & Normal \\
\hline $\mathrm{R}$ cervical paraspinals & $\mathrm{b}$ & & \\
\hline $\mathrm{R}$ thoracic paraspinals & $\mathrm{b}$ & & \\
\hline \multicolumn{4}{|c|}{$\begin{array}{l}\text { Abbreviations: ADM = abductor digiti minimi; } A P B=\text { abductor pollicis brevis; CMAP = compound muscle action potential; EDB = extensor digitorum brevis; } \\
\text { EDC = extensor digitorum communis; EIP = extensor indicis proprius; } F D I=\text { first dorsal interosseous; Fibs } / P S W s=\text { fibrillation potentials or positive sharp } \\
\text { waves; SNAP = sensory nerve action potential. } \\
\text { a Abnormal. } \\
\text { b Difficulty with relaxation impeded analysis. }\end{array}$} \\
\hline
\end{tabular}




\section{Section 3}

Decreased amplitude of sensory responses suggests a lesion at or distal to the dorsal root ganglia, since sensory roots proximal to the dorsal root ganglia are not assessed with NCS. EMG further refines localization and provides evidence for the chronicity of the lesion. When a muscle is denervated, individual muscle fibers fire spontaneously, resulting in fibrillation potentials and positive sharp waves (Fibs/PSWs). Spontaneous activity in the paraspinal muscles suggests proximal denervation (such as in radiculopathy) because the paraspinals are supplied by the dorsal rami. Spontaneous activity signals new nerve twigs to arise from intact nerves nearby to supply the denervated muscle fibers. Previously denervated muscles can be reinnervated by axonal regeneration and sprouting nerve twigs from unaffected nearby axons. These newly formed axons are thinly myelinated, so conduct slower. Also, newly regenerated neuromuscular junctions are less stable. As a result, the duration of motor unit action potentials (MUAP) becomes prolonged and the morphology becomes more polyphasic. As the connections mature, previous atrophic fibers grow, and because more muscle fibers are now innervated from single motor units, the amplitude of the MUAP also becomes larger over time. Thus, increased duration and amplitude of MUAPs on needle EMG are signs of reinnervation. The force of a muscle contraction is a function of the number and speed of motor units. When denervation occurs, the remaining motor units fire faster than is appropriate for the number of motor units firing, referred to as reduced recruitment.

Our patient had an absent right radial sensory response and decreased left radial and bilateral median responses. Radial motor response was decreased on the left and absent on the right. So the lesion is at or distal to the dorsal root ganglia. On EMG, there were fibs/PSWs in the deltoid, pronator teres, and extensor digitorum communis, indicating denervation in the distribution of the axillary, median, and radial nerves, respectively. Evaluation of the cervical paraspinals was impeded by incomplete muscle relaxation. Reduced recruitment was present in our patient's deltoid and biceps, suggesting denervation in the axillary and musculocutaneous distributions. There was motor unit remodeling in the biceps, indicating reinnervation in the distribution of the musculocutaneous nerve. Based on the multiplicity of nerve territories involved, we conclude that there is electrodiagnostic evidence for a patchy brachial plexopathy.

\section{Questions for consideration:}

1. What is the differential diagnosis of brachial plexopathy?

2. What additional testing is indicated?

GO TO SECTION 4 


\section{Section 4}

Etiologies of brachial plexopathy include the following:

- Trauma. Shoulder trauma tends to affect the upper plexus whereas traction injury to the arm affects the lower plexus.

- Inflammation. Idiopathic brachial plexus neuropathy, or Parsonage-Turner syndrome, is an inflammatory brachial plexopathy characterized by severe pain at onset followed by weakness and sensory disturbance.

- Infectious. Lyme disease can cause an asymmetric polyradiculopathy or multiple mononeuropathies.

- Neoplastic. Brachial plexopathy can be caused by breast or lung cancer or lymphoma, or radiation to the region of the plexus. Radiation plexopathy tends to be painless, affecting the upper plexus, whereas malignant brachial plexus infiltration tends to be painful, affecting the lower plexus. Myokymic discharges on EMG are associated with radiation-induced plexopathy.

- Hereditary. Hereditary neuralgic amyotrophy causes recurrent brachial plexopathies with pain similar to Parsonage-Turner syndrome.

Our patient had no history of trauma, cancer, or radiation therapy. Laboratory evaluation demonstrated normal hemoglobin Alc, erythrocyte sedimentation rate, C-reactive protein, and serum protein electrophoresis, and negative Lyme antibodies. Imaging was obtained to further evaluate the brachial plexus.

\section{Question for consideration:}

1. What findings would be expected on brachial plexus MRI in inflammatory or infiltrative brachial plexopathy? 


\section{Section 5}

Nerve root enlargement, peripheral nerve enlargement, or enhancement of these structures is a sign of inflammatory or infectious process. Our patient's MRI of the brachial plexus did not show compression, nerve enlargement, or nerve enhancement.

The patient provided additional history. Ten years prior to presentation, he had left hand numbness and weakness associated with shoulder pain that lasted 3 months and resolved completely. His brother had multiple episodes of wrist drop since the age of 7 that improved over a period of months, but left residual numbness and weakness such that he wore a wrist brace. His sister also wore a wrist brace. His maternal grandfather had 3 episodes of transient foot drop. His daughter had numbness and pain in her right arm that lasted 3 months and resolved completely.

1. What hereditary disease could account for patient's symptoms and what testing is required for definitive diagnosis?

2. What additional features on examination would support this diagnosis?

GO TO SECTION 6 


\section{Section 6}

Hereditary neuralgic amyotrophy (HNA) is an autosomal dominant disorder causing recurrent episodes of brachial plexitis. It is associated with a mutation in the Septin 9 gene on chromosome 17. ${ }^{1}$ Septins are GTPases that interact with the cytoskeleton and are involved in cell division. The exact mechanism by which septin dysfunction causes recurrent brachial plexopathy is unknown. Our patient had a mutation in the Septin 9 gene.

HNA is associated with dysmorphic features including cleft palate, hypotelorism (shortened distance between the eyes), short stature, and extra skin folds on the neck. ${ }^{2,3}$ Our patient was shorter than average at $5^{\prime} 4^{\prime \prime}$. He had hypotelorism with interpupillary distance of $5.6 \mathrm{~cm}$. He had several horizontal skin folds of the anterior neck. His mother had a cleft palate.

Attacks of brachial plexitis in HNA can be brought on by stress, illness, or surgery. There are some reports of lumbosacral plexus involvement. Symptoms typically improve over months, but residual weakness may occur. Patients typically have a few episodes throughout their lifetime. ${ }^{2}$ While there is no definitive treatment, splinting and physical therapy can prevent contractures and lessen disability. Corticosteroids may reduce pain if initiated early after symptom onset. ${ }^{4}$ In one case, IV immunoglobulin was believed to be helpful. ${ }^{5}$ Our patient experienced gradual improvement in weakness with supportive care, namely physical and occupational therapy. Ten months after symptom onset, he had difficulty typing and reported ongoing pain and sensory abnormalities, but had improved fine motor ability to the point that he could clip his fingernails.

\section{Author contributions}

Dr. Foster drafted the initial manuscript, revised the manuscript, and was involved in the clinical care of the patient. Dr. Amato revised the manuscript and was involved in the clinical care of the patient. Dr. Berkowitz revised the manuscript.

\section{Study funding}

No targeted funding reported.

\section{Disclosure}

L.A. Foster reports no disclosures relevant to the manuscript. A.A. Amato is an associate editor for Neurology ${ }^{\circledR}$. A.L. Berkowitz reports no disclosures relevant to the manuscript, but receives royalties from Clinical Pathophysiology Made Ridiculously Simple (MedMaster), The Improvising Mind (Oxford), and Clinical Neurology and Neuroanatomy: A Localizationbased Approach (McGraw-Hill). Go to Neurology.org/N for full disclosures.

\section{References}

1. Kuhlenbäumer G, Hannibal MC, Nelis E, et al. Mutations in SEPT9 cause hereditary neuralgic amyotrophy. Nat Genet 2005;37:1044-1046.

2. Jeannet PY, Watts GD, Bird TD, Chance PF. Craniofacial and cutaneous findings expand the phenotype of hereditary neuralgic amyotrophy. Neurology 2001;57: 1963-1968.

3. Ueda M, Kawamura N, Tateishi T, et al. Phenotypic spectrum of hereditary neuralgic amyotrophy caused by the SEPT9 R88W mutation. J Neurol Neurosurg Psychiatry 2010;81:94-96.

4. Klein CJ, Dyck PJB, Friedenberg SM, Burns TM, Windebank AJ, Dyck PJ. Inflammation and neuropathic attacks in hereditary brachial plexus neuropathy. J Neurol Neurosurg Psychiatry 2002;73:45-50.

5. Ardolino G, Barbieri S, Priori A. High dose intravenous immune globulin in the treatment of hereditary recurrent brachial plexus neuropathy. J Neurol Neurosurg Psychiatry 2003;74:550-551.

\section{Disputes \& Debates: Rapid online correspondence}

The editors encourage comments on recent articles through Disputes \& Debates:

Access an article at Neurology.org/ $\mathrm{N}$ and click on "COMMENT" beneath the article header. Responses will be posted within 3 business days.

Before submitting a comment to Disputes \& Debates, remember the following:

- Disputes \& Debates is restricted to comments about studies published in Neurology within the last eight weeks

- Read previously posted comments; redundant comments will not be posted

- Your submission must be 200 words or less and have a maximum of five references; reference one must be the article on which you are commenting

- You can include a maximum of five authors (including yourself) 


\title{
Neurology
}

\section{Clinical Reasoning: A 60-year-old man with arm weakness and numbness}

\author{
Laura A. Foster, Anthony A. Amato and Aaron L. Berkowitz
}

Neurology 2018;90;190-196

DOI 10.1212/WNL.0000000000004867

This information is current as of January 22, 2018

$\begin{array}{ll}\begin{array}{l}\text { Updated Information \& } \\ \text { Services }\end{array} & \begin{array}{l}\text { including high resolution figures, can be found at: } \\ \text { http://n.neurology.org/content/90/4/190.full }\end{array} \\ \text { References } & \text { This article cites } 5 \text { articles, } 4 \text { of which you can access for free at: } \\ \text { http://n.neurology.org/content/90/4/190.full\#ref-list-1 } & \text { This article, along with others on similar topics, appears in the } \\ \text { following collection(s): } & \text { All Genetics } \\ \text { http://n.neurology.org/cgi/collection/all_genetics } \\ \text { All Neuromuscular Disease } \\ \text { http://n.neurology.org/cgi/collection/all_neuromuscular_disease } \\ \text { EMG } \\ \text { http://n.neurology.org/cgi/collection/emg } \\ \\ \text { Information about reproducing this article in parts (figures,tables) or in } \\ \text { its entirety can be found online at: } \\ \text { http://www.neurology.org/about/about_the_journal\#permissions } \\ \text { Information about ordering reprints can be found online: } \\ \text { hermissions \& Licensing } \\ \text { http://n.neurology.org/subscribers/advertise }\end{array}$

Neurology ${ }^{\circledR}$ is the official journal of the American Academy of Neurology. Published continuously since 1951 , it is now a weekly with 48 issues per year. Copyright Copyright (C) 2018 American Academy of Neurology. All rights reserved. Print ISSN: 0028-3878. Online ISSN: 1526-632X.

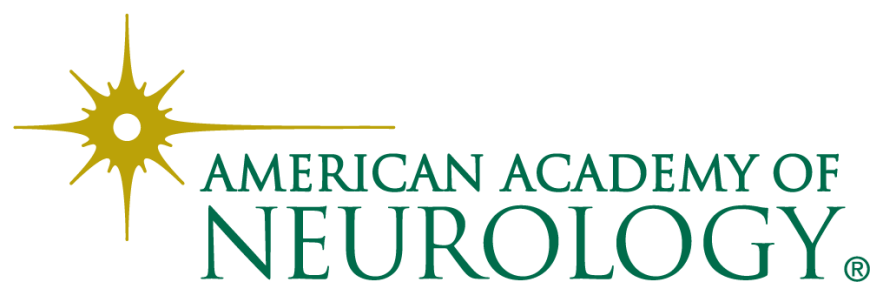

